\title{
PENETRATING KERATOPLASTY IN THE MENTALLY RETARDED
}

\author{
A. M. McELVANNEY and H. P. ADHIKARY \\ Preston
}

\begin{abstract}
SUMMARY
Penetrating keratoplasty is infrequently performed in the mentally retarded due to the high risk of serious post-operative complications, in particular wound rupture and severe inflammation of the graft. Graft survival is hindered by the patient's tendency for eye rubbing and possibly self-inflicted injury. Adequate nursing support is essential to ensure strict compliance with post-operative treatment. A retrospective study of corneal graft outcomes in mentally retarded patients was undertaken to assess graft survival, visual rehabilitation, post-operative complications and the influence on social behaviour. Six cases of penetrating keratoplasty performed in mentally retarded patients by one surgeon are presented. A continuous 10-0 nylon suture was employed in all cases. In 2 cases surgery was undertaken following perforation of the globe in patients with Down's syndrome. The grafts were retained in all cases and 2 patients achieved reasonably good acuity, although formal visual acuity assessment in these patients is limited. Penetrating keratoplasty in mentally retarded patients is a potentially hazardous procedure and patients require close supervision and good support care. This series demonstrates that relatively successful outcomes can be obtained in some mentally retarded patients.
\end{abstract}

Visual handicap is known to be more prevalent in the mentally retarded than in the general population, and may be correlated with the severity of mental retardation. ${ }^{1}$ In particular, keratoconus affects around $5 \%$ of the mentally retarded, ${ }^{2}$ and in Down's syndrome keratoconus has been reported to occur in approximately $5-30 \%$ of patients. ${ }^{1-4}$ These patients often present with advanced acute hydrops, 5,6 often resulting in marked visual disability. Penetrating keratoplasty may be the only option for restoring vision in these patients, but may be regarded unduly

From: Royal Preston Hospital, Preston, Lancs, UK.

Correspondence to: Miss A. M. McElvanney, Eye Department, Royal Surrey County Hospital, Egerton Road, Guildford, Surrey GU2 5XX, UK. hazardous due to difficulties with early reporting of postoperative complications, the tendency for eye rubbing and self-inflicted injury, the risk of infection and the association with allergic disease..$^{1-3,5}$

\section{PATIENTS AND METHODS}

Six mentally retarded patients underwent penetrating keratoplasty (PKP) between April 1985 and November 1994. Five patients had Down's syndrome and 1 had Dubowitz syndrome. Age range was 19-21 years and 3 of the 6 patients were in residential care (Table I). Follow-up ranged from 18 months to 6 years. The indication for PKP was severe keratoconus, with acute hydrops being present in 4 cases, 2 of which had perforated. One patient underwent PKP to each eye on separate occasions and in 2 patients PKP was combined with cataract extraction and intraocular lens implant (IOL). The case details and results are summarised in Table II.

\section{Surgical Technique}

The surgical technique of PKP has been well defined. ${ }^{7}$ All grafts were performed by a single surgeon using a standard technique. A diamond knife was used to excise recipient cornea following trephining and donor material was sutured using continuous $10-0$ nylon.

\section{RESULTS}

Of 7 grafts performed in 6 patients, one failed following dendritic. ulceration of the graft and secondary bacterial keratitis (case 2), and one developed bullous keratopathy from endothelial failure (case 6). One patient underwent a successful HLA-matched re-graft, after failure of the first from chronic rejection (case 1). The remainder of the keratoplasties stayed clear, although significant corneal neovascularisation developed in one eye. Visual improvement was apparent by the improved social behaviour of the patients. In particular, patients demonstrated less aggressive behaviour 
Table I. Summary of age, sex, mental condition and pre-operative visual acuities of the six patients

\begin{tabular}{ccccccc}
\hline Case no. & Age (years) & Sex & Condition & Institutionalised & Acuity of operated eye & Acuity of fellow eye \\
\hline 1 & 19 & M & Dubowitz & No & HM & CF \\
2 & 20 & F & Down's & Yes & N/A & N/A \\
3 & 15 & M & Down's & No & HM & $6 / 5$ \\
4 & 19 & M & Down's & No & RE = PL, LE $=$ HM & LE =6/36 at time of R PKP \\
5 & 18 & M & Down's & Yes & HM & CF \\
6 & 21 & F & Down's & Yes & \\
\hline
\end{tabular}

$\mathrm{RE}$, right eye; LE, left eye; N/A, not ascertained.

and required less sedation, increased navigational ability was apparent and social interaction improved.

Patient 1 developed graft failure at 5 months and was re-grafted 4 months later with HLA-matched donor material. Outpatient review identified a loose corneal suture 7 months post-operatively and this was subsequently removed under general anaesthetic. After 3 years vision in this eye was $6 / 36$.

Patient 2 was severely mentally retarded and formal visual acuity assessment was not possible. One month post-operatively she developed a painful red eye and underwent examination under anaesthesia (EUA) that revealed dendritic ulceration of the cornea. Resolution of the ulcer resulted in corneal scarring and graft failure at 2 months.

Patient 3 was able to cooperate with outpatient examination and EUA was not required. The graft remained clear at 2 years and vision was recorded as 6/36.

Patient 4 cooperated well with outpatient review. EUA was undertaken at 10 months for a loose corneal suture which was removed. At 18 months vision was $6 / 36$ and the graft remained clear.

Patient 5 initially underwent PKP to the right eye for acute hydrops with perforation (Fig. 1). The extent of corneal involvement necessitated freehand grafting. A large donor button was therefore trephined and subsequently trimmed to fit the recipient corneal bed (Fig. 2). The corneal suture loosened at 3 months requiring EUA and suture removal at this time. Post-operatively, vascularisation developed in the graft with deep vessels particularly affecting the inferior quadrants. PKP was undertaken to the left eye when visual acuity in this eye dropped to hand movements due to progression of keratoconus. Cataract formation developed 10 months post-operatively and cataract extraction with lens implant combined with suture removal was subsequently undertaken. Visual acuities of $6 / 60$ in the right eye and 6/36 in the left were recorded.

Patient 6 underwent PKP combined with cataract extraction and lens implant. A large donor button was required due to extensive corneal scarring and thinning. The continuous suture loosened at 4 months, EUA was performed and the suture removed. However, the graft failed as a result of corneal decompensation and bullous keratopathy was apparent at 6 months.

\section{DISCUSSION}

There is limited experience of penetrating keratoplasty undertaken in the mentally retarded. Most series refer to patients with Down's syndrome undergoing PKP following episodes of acute hydrops. ${ }^{2,5,8,9}$ It is generally believed that mentally retarded patients may have a poorer post-operative outcome than the normal keratoconus population as a result of cooperation difficulties, the fact that many are institutionalised and may not receive observation by a single dedicated carer, and the increased incidence of eye rubbing and self-inflicted trauma. These factors may contribute to increase the risk of possible complications. ${ }^{10}$ Surgery itself may be technically difficult, as marked peripheral corneal oedema may be present in eyes with acute hydrops. Graft rejection may result from self-traumatisation and non-compliance with the post-operative regime.

Table II. Summary of pre-operative status and post-operative outcomes and follow-up

\begin{tabular}{|c|c|c|c|c|c|c|}
\hline Case no. & Pre-op. VA & Pre-op. status & Graft size $(\mathrm{mm})$ & Post-op. course & Result VA & Follow-up \\
\hline 1 & HM & Keratoconus & $d=7.5, r=7.0$ & Rejection at 5 months & Re-graft clear, $6 / 36$ & 3 years \\
\hline 2 & N/A & $\begin{array}{l}\text { Keratoconus and } \\
\text { hydrops perforation }\end{array}$ & $\begin{array}{l}d=8.5, r=8.0 ;+ \\
\mathrm{ECCE}+\mathrm{IOL}\end{array}$ & $\begin{array}{l}\text { Dendritic ulcer; } \\
\text { bacterial keratitis }\end{array}$ & Graft failure & 4 years \\
\hline 3 & $\mathrm{CF}$ & $\begin{array}{l}\text { Keratoconus and } \\
\text { hydrops }\end{array}$ & $d=7.5, r=7.25$ & Nil & Graft clear, $6 / 36$ & 2 years \\
\hline 4 & $\mathrm{HM}$ & $\begin{array}{l}\text { Keratoconus and } \\
\text { hydrops }\end{array}$ & $d=8.0, r=7.5$ & Nil & Graft clear, $6 / 36$ & 18 months \\
\hline 5 & $\begin{array}{l}\mathrm{RE}=\mathrm{PL} \\
\mathrm{LE}=\mathrm{HM}\end{array}$ & $\begin{array}{l}\text { Keratoconus } \\
\text { (R hydrops }+ \\
\text { perforation) }\end{array}$ & $\begin{array}{l}\mathrm{RE} d=11.0 \\
(\text { trimmed) } r=9.5 ; \\
\text { LE } d=8.5, r=8.0\end{array}$ & $\mathrm{R}$ corneal vessels & $\begin{array}{l}\text { Grafts clear, RE = } \\
6 / 60, \mathrm{LE}=6 / 36\end{array}$ & $\begin{array}{l}\text { RE } 6 \text { years, } \\
\text { LE } 3 \text { years }\end{array}$ \\
\hline 6 & HM & Keratoconus & $\begin{array}{l}d=11.0, r=10.5 ;+ \\
\mathrm{ECCE}+\mathrm{IOL}\end{array}$ & $\begin{array}{l}\text { Decompensation; } \\
\text { bullous keratopathy }\end{array}$ & Failed graft & 3 years \\
\hline
\end{tabular}

VA, visual acuity; RE, right eye; LE, left eye; ECCE, extracapsular cataract examination; IOL, intraocular lens. 


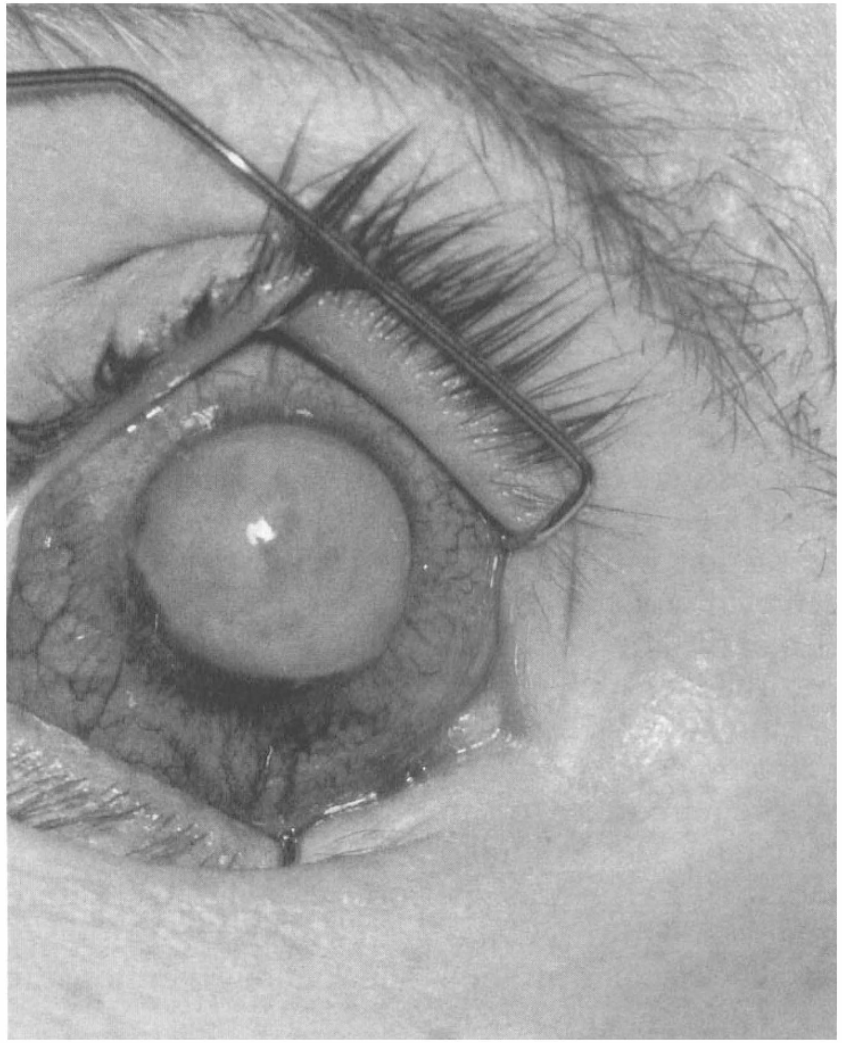

Fig. 1. Case 5. Right eye before keratoplasty.

Wound rupture may occur, and may not be immediately apparent to the carers; thus complications may present at a later stage. Furthermore, blepharitis is often present in the mentally retarded patient, ${ }^{11}$ which could influence the graft environment. In addition, the strong association of keratoconus with allergic eye disease may result in corneal vascularisation and further compromise the keratoplasty.

PKP was undertaken in 2 patients in this series for perforation following acute hydrops, and although graft failure occurred in one case, the eye was retained. In the other case, vascularisation of the graft occurred; however, a visual acuity of 6/60 was maintained post-operatively. In 5 eyes the decision to undertake PKP was based on poor visual acuity in the fellow eye. One patient (case 3 ) had $6 / 5$ vision in the fellow eye, but in view of the mild retardation and previously good acuity in the affected eye it was anticipated that PKP would have a successful outcome.

In our study 2 patients developed graft failure, and a third had a successful HLA-matched re-graft after a rejection episode. The 2 failed grafts occurred in the two most severely retarded patients, who were both institutionalised, and in whom PKP was combined with cataract extraction; one PKP was undertaken for perforation of the cornea.

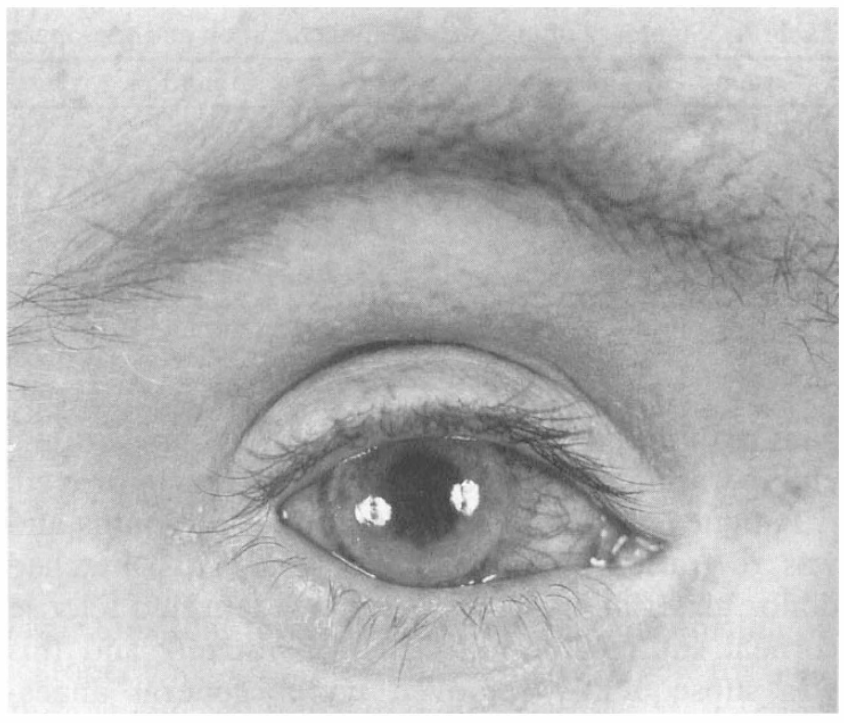

Fig. 2. Case 5. Right eye 2 weeks after keratoplasty.

EUA in Down's syndrome is not without hazard due to underlying cardiovascular and other anomalies. EUA was therefore only undertaken to remove corneal sutures, or when examination in the outpatient department was not permitted through lack of cooperation. It was the aim to remove the corneal suture by 12 months post-operatively. However, in several cases loosening of the suture occurred at an earlier stage of follow-up and necessitated suture removal.

Visual acuity testing in these patients was limited due to poor cooperation, but post-operatively some measure of improvement in navigational vision was noted as well as improved behavioural patterns with less aggressive behaviour, suggesting a successful outcome. A continuous suture was used in all cases. This technique required less time to complete than the placement of interrupted sutures and subsequently reduced anaesthetic time. It was also considered that problems related to protruding knots might be avoided. Although loosening of the continuous suture can occur, wound rupture was not a problem in any case, and previous reports have suggested no difference in outcome with regard to wound rupture with the use of either continuous or interrupted sutures. ${ }^{12}$

Some authors have reported good results following epikeratophakia for keratoconus in the mentally retarded. ${ }^{11}$ It may be particularly useful in those with only mild scarring, with the added advantage of reinforcing an ectatic cornea. However, in all our cases, this was contraindicated by the severe central scarring and unresolved hydrops of the cornea.

Finally, good post-operative care is essential in order to ensure early reporting of adverse post. operative events, and the adherence to regular instillation of steroid and antibiotic eye drops, 
which must be emphasised to carers. Increasingly, Down's syndrome patients are being cared for at home $^{1}$ and a single carer may have increased awareness of day-to-day changes in the patient's ocular status.

In conclusion, although PKP undertaken in mentally retarded patients may have an increased risk of failure, it may be a worthwhile procedure in those patients severely compromised by central corneal scarring and hydrops and may result in improved vision.

Key words: Penetrating keratoplasty, Acute hydrops, Mental retardation.

\section{REFERENCES}

1. Jacobson L. Ophthalmology in mentally retarded adults: a clinical survey. Acta Ophthalmol (Stockh) 1988;66:457-62.

2. Haugen $\mathrm{OH}$. Keratoconus in the mentally retarded. Acta Ophthalmol (Stockh) 1992;70:111-4.

3. Walsh SZ. Keratoconus and blindness in 469 institutionalised subjects with Down syndrome and other causes of mental retardation. J Ment Defic Res 1981; 25:243-51.
4. Cullen JF. Blindness in mongolism (Down's syndrome). Br J Ophthalmol 1963;47:331-3.

5. Slusher MM, Laibson PR, Mulberger RD. Acute keratoconus in Down's syndrome. Am J Ophthalmol 1968;66:1137-43.

6. Pierse $\mathrm{D}$, Eustace $\mathrm{P}$. Acute keratoconus in mongols. $\mathrm{Br}$ J Ophthalmol 1971;55:50-4.

7. Kaufman HE, McDonald MB, Barron BA, Wilson SE. In: Corneal and refractive surgery. Philadelphia: JB Lippincott, 1992:15-105.

8. Frantz JM, Insler MS, Hagenah M, McDonald MB, Kaufman HE. Penetrating keratoplasy for keratoconus in Down's syndrome. Am J Ophthalmol 1990;109: 143-7.

9. Tuft SJ, Gregory WM, Buckley RJ. Acute corneal hydrops in keratoconus. Ophthalmology 1994;101: 1738-44.

10. Sharif KW, Casey TA. Penetrating keratoplasty for keratoconus: complications and long-term success. $\mathrm{Br} \mathbf{J}$ Ophthalmol 1991;75:142-6.

11. Hovding G, Haugen OH, Bertelsen T. Epikeratophakia for keratoconus in mentally retarded patients: the use of fresh, free-hand made lamellar grafts. Acta Ophthalmol (Stockh) 1992;70:730-5.

12. Binder PS, Abel R Jr, Polack FM, Kaufman HE. Keratoplasty wound separations. Am J Ophthalmol 1975;80:109-15. 